\title{
Pengoptimuman Parameter untuk Penurunan Diimida Getah Asli Cecair dalam Sistem Hidrazin Hidrat/Hidrogen Peroksida Menggunakan Kaedah Rangsangan Permukaan (RSM) \\ (Parameter Optimisation for Diimide Reduction of Liquid Natural Rubber in Hydrazine Hydrate/Hydrogen Peroxide System using Response Surface Methodology (RSM))
}

\author{
MUHAMMAD JEFRI MOHD YUSOF, NUR AIDASYAKIRAH MOHD TAHIR, \\ FAZIRA FIRDAUS \& SITI FAIRUS M. YUSOFF*
}

\begin{abstract}
ABSTRAK
Getah asli cecair (LNR) dihasilkan daripada proses penyahpolimeran getah asli yang menghasilkan rantaian polimer lebih pendek dan berat molekular kurang daripada $10^{5}$. Namun, LNR masih mempamerkan tahap degradasi dan ketahanan termal yang rendah seperti getah asli, disebabkan oleh kehadiran ikatan karbon ganda dua pada rantaian polimer. Dalam kajian ini, penurunan diimida menggunakan pengoksidaan hidrazin hidrat dengan hidrogen peroksida dijalankan untuk menghidrogenkan unit tidak tepu LNR. LNR terhidrogen (HLNR) dicirikan menggunakan spektrometer infra-merah (FTIR) dan spektrometer resonans magnetik nuklear (NMR). Pengoptimuman parameter tindak balas dilakukan dengan memanipulasi parameter masa dan suhu tindak balas berdasarkan kaedah rangsangan permukaan (RSM) dengan 5-aras-2-faktor reka bentuk komposit putaran tengah (CCRD). Satu model kuadratik yang signifikan telah dihasilkan untuk menghubungkan dua parameter tersebut dengan nilai $R^{2}$ adalah 0.9986, menunjukkan bahawa model yang terhasil adalah sangat sepadan dengan data uji kaji. Keputusan kajian menunjukkan bahawa peratus penghidrogenan boleh ditingkatkan sehingga 91.2\%. Seterusnya, berdasarkan RSM, parameter yang optimum bagi penurunan diimida LNR ini didapati pada suhu $55.9^{\circ} \mathrm{C}$ selama 6.7 jam, menghasilkan $80.2 \%$ HLNR. Kajian ini telah menunjukkan reka bentuk uji kaji secara statistik yang novel bagi menghidrogenkan LNR. Pelbagai variasi peratus penghidrogenan produk HLNR dalam kajian ini menyumbang kepada lebih banyak aplikasi produk yang memerlukan peratusan ketepuan unit yang tertentu.
\end{abstract}

Kata kunci: Getah asli cecair; kaedah rangsangan permukaan (RSM); penghidrogenan; pengoptimuman; reka bentuk komposit putaran tengah (CCRD)

\section{ABSTRACT}

Liquid natural rubber (LNR) derives from depolimerisation of natural rubber resulting in shorter polymeric chains and lower molecular weight of less than $10^{5}$. However, LNR still exhibits weak degradation and thermal resistance of natural rubber due to the presence of carbon-carbon double bonds along its backbone. In this research, diimide reduction via oxidation of hydrazine hydrate with hydrogen peroxide was used to hydrogenate LNR to saturate its chemical structure. Hydrogenated LNR (HLNR) was characterized using Fourier-transform infrared (FTIR) and nuclear magnetic resonance (NMR) spectroscopies. The optimization of reaction conditions was accomplished by manipulating time and temperature parameters based on response surface methodology (RSM) of 5-level-2-factor central composite rotatable design (CCRD). A significant quadratic model was generated to correlate those two parameters with $R^{2}$ value of 0.9986 , indicating that the model was remarkably fit with the experimental data. The results showed that hydrogenation degree of the product (HLNR) could be extended to 91.2\%. Subsequently, the optimum conditions for diimide reduction of LNR were found to be at $55.9^{\circ} \mathrm{C}$ for $6.7 \mathrm{~h}$, yielding $80.2 \%$ HLNR. This study has demonstrated the novel statistical design of experiment to hydrogenate LNR as a new starting material. The variation of hydrogenation degrees of the products has opened up more potentials for industrial and application purposes as they are composed of different percentages of saturated and saturated units.

Keywords: Central composite rotatable design (CCRD); hydrogenation; liquid natural rubber; optimization; response surface methodology (RSM)

\section{PENGENALAN}

Polimer baharu dengan ciri-ciri ketahanan sifat fizikal dan kimia yang ditingkatkan banyak dihasilkan menggunakan kaedah pengubahsuaian secara kimia (Leimgruber \& Trimmel 2015). Polimer tidak tepu selalunya diubah suai kerana kehadiran ikatan karbon ganda dua yang boleh dimanipulasikan untuk membentuk struktur baru melalui beberapa siri tindak balas kimia (Fainleib et al. 2013). Penurunan unit tidak tepu menjadikannya lebih tahan terhadap degradasi termal dan oksidatif dengan 
pertambahan unit tepu pada tulang belakang polimer (Simma et al. 2009; Zirnstein et al. 2018). Sebagai contoh, getah nitril-butadiena terhidrogen mempunyai ketahanan hakisan yang tinggi pada suhu tinggi maka sangat sesuai dijadikan sebagai bahan penebat dalam enjin (Zirnstein et al. 2018).

Getah asli (NR) adalah elastomer dengan berat molekul 1 hingga 2 juta g/mol. Monomer bagi NR adalah 2-metil-1,3-butadiena atau lebih dikenali sebagai isoprena. Getah asli cecair (LNR) pula merupakan hasil ubah suai NR melalui proses penyahpolimeran (Jamaluddin et al. 2016). LNR mempunyai beberapa kelebihan berbanding getah sintetik. Pertama sekali, langkah penghasilan LNR adalah lebih mesra alam dan menjimatkan tenaga berbanding getah sintetik yang memerlukan degradasi secara metatesis dan pemotongan rantaian menggunakan asid kuat (Trovatti et al. 2017). Seterusnya, NR yang digunakan untuk menyediakan LNR datang daripada sumber alam yang boleh diperbaharui (Onoji et al. 2016; Yuan et al. 2017). LNR mendapat permintaan di pasaran disebabkan aplikasinya sebagai pelekat, pengserasi, pengubah suai kelikatan dan pemplastik untuk meningkatkan pemprosesan produk getah (Radabutra et al. 2017). Namun, LNR memiliki struktur kimia yang masih sama seperti unit tidak tepu NR yang mempunyai ketahanan yang rendah terhadap degradasi termal dan oksidatif (Thongnuanchan et al. 2015).

Penghidrogenan adalah salah satu kaedah yang digunakan untuk mengurangkan unit tidak tepu dalam rantaian poliisoprena; dengan mangkin atau tanpa mangkin (Taksapattanakul et al. 2017; Wu et al. 2014). Kaedah penghidrogenan tanpa mangkin lebih digemari kerana kaedah ini tidak memerlukan keadaan tindak balas yang ekstrem sebagaimana kaedah penghidrogenan bermangkin yang memerlukan tekanan gas dan suhu yang tinggi serta penggunaan reaktor (Sakorn et al. 2016). Penghidrogenan tanpa mangkin bergantung kepada penghasilan spesies diimida daripada tindak balas sumber organik seperti penyahkarboksilan azodikarboksilat, pengoksidaan hidrazin dan rawatan termal arinisulfonilhidrazida yang telah terbukti mampu menurunkan polimer tidak tepu (Han et al. 2014; Yusof et al. 2017). Penurunan diimida sebagai langkah penghidrogenan telah diperkenalkan oleh Wideman pada tahun 1984 dan kaedah ini semakin dikembangkan dan dioptimumkan oleh para penyelidik (Sakorn et al. 2016; Taksapattanakul et al. 2017).

Tindak balas ini boleh dijalankan pada tekanan atmosfera sekeliling dengan suhu tindak balas sederhana dan menggunakan alatan radas makmal yang biasa (Azhar et al. 2015; Yusof et al. 2017). Tambahan pula, penggunaan medium akues dalam tindak balas ini memudahkan penyingkiran pelarut organik toksik yang digunakan (toluena) (Ji et al. 2017). Simma et al. (2009) mencadangkan mekanisme bagi penghasilan unit diimida dan proses penghidrogenan ke atas poliisoprena sebagaimana yang ditunjukkan dalam Rajah 1 .

Kaedah rangsangan permukaan (RSM) adalah sejenis perisian statistik yang sangat berguna dalam

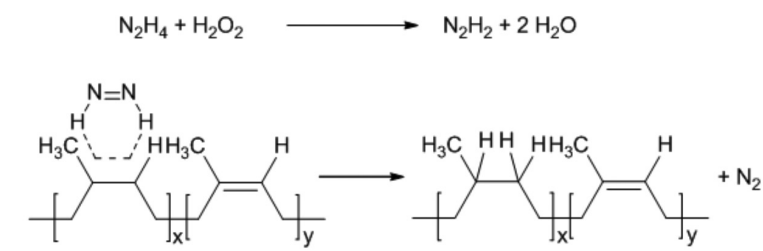

RAJAH 1. Penurunan diimida poliisoprena (Simma et al. 2009)

meminimumkan bilangan uji kaji yang perlu dijalankan dan mengenal pasti hubungan antara pemboleh ubah yang mempengaruhi tindak balas (Salinas et al. 2016). Alshaibani et al. (2014) telah menggunakan kaedah ini untuk mengoptimumkan penghidrogenan minyak kelapa sawit. Mereka mendapati pertambahan suhu dan keadaan beralkali menghasilkan peratus pertukaran unit tepu yang lebih tinggi. Penyediaan mangkin yang digunakan dalam kajian mereka adalah berdasarkan kajian pengoptimuman oleh RSM yang membantu dalam pertukaran $47 \%$ produk terhidrogen mereka (Alshaibani et al. 2014). Sementara itu, Cepeda dan Calvo (2008) telah mengkaji penghidrogenan minyak bunga matahari menggunakan RSM dengan mengoptimumkan suhu tindak balas, tekanan dan kuantiti mangkin. Kedua-dua nilai jangkaan dan eksperimental menunjukkan data yang hampir sama.

Bagi kajian ini, LNR telah dihidrogenkan menggunakan sistem $\mathrm{HH} / \mathrm{H}_{2} \mathrm{O}_{2}$. Rantaian polimernya yang pendek dijangka memberi permukaan terdedah yang lebih luas bagi penembusan spesis diimida ke atas rantaian LNR (Taksapattanakul et al. 2017). Kami melaporkan keputusan kajian yang melibatkan kesan suhu dan masa tindak balas dalam pengoptimuman penghidrogenan LNR berdasarkan reka bentuk eksperimental yang dicadangkan oleh RSM.

\section{UJI KAJI}

\section{BAHAN}

Getah asli (NR) yang telah digunakan diperoleh daripada Institut Penyelidikan Getah Malaysia (RRIM). Toluena dan metanol telah dibeli daripada RM Chemical. Metilena biru, Ros Bengal, hidrazina dan hidrogen peroksida telah dibeli daripada Sigma Aldrich. Natrium dodesil sulfat dan asid borik telah dibeli daripada Systerm.

\section{PENYEDIAAN LNR}

LNR telah disediakan dengan menggunakan kaedah degradasi LNR bersama fotopemeka (Kargarzadeh et al. 2014; Tahir et al. 2017). $1 \mathrm{~kg}$ NR yang telah dipotong kepada saiz kecil direndam dalam pelarut toluena selama semalaman. Ros Bengal dan metilena biru sebagai fotopemeka dan $10 \mathrm{~mL}$ metanol dimasukkan ke dalam campuran. Campuran tersebut dikacau menggunakan pengacau mekanikal selama 10 hari dengan kehadiran cahaya tampak. LNR yang diperoleh diemparkan selama 4 min pada kelajuan $3000 \mathrm{rpm}$. Dua lapisan getah terbentuk 
dan lapisan atas getah telah digunakan kerana mengandungi pembentukan gel yang minimum (Ibrahim et al. 2016).

\section{PENURUNAN DIIMIDA LNR}

Emulsi LNR (5 g), natrium dodesil sulfat $(0.00035 \mathrm{~mol}$, $0.10 \mathrm{~g}$ ) sebagai surfaktan, beberapa titis minyak silikon dan air suling $(50 \mathrm{~mL})$ dimasukkan ke dalam kelalang dasar bulat berleher tiga. Selepas dikacau selama $30 \mathrm{~min}$, hidrazin hidrat $(0.64 \mathrm{~mol}, 20.1 \mathrm{~g})$ ditambah dan dikacau selama $30 \mathrm{~min}$.

Sistem ini dipanaskan semasa dikacau. Larutan hidrogen peroksida and asid borik disediakan dengan melarutkan $1.5 \mathrm{~g}$ asid borik $(0.024 \mathrm{~mol})$ dalam $40 \mathrm{~mL}$ hidrogen peroksida. Kemudian, larutan ini ditambah secara titis demi titis pada masa tindak balas yang berbeza. Produk diperoleh dengan cara penggumpalan dalam etanol. Kemudian, produk dikeringkan dalam ketuhar vakum sekurang-kurangnya selama 12 jam.

\section{PENGOPTIMUMAN MENGGUNAKAN RSM}

Tindak balas ini dijalankan pada suhu dan masa tindak balas yang berbeza yang memerlukan 13 kali ulangan. Jadual 1 menunjukkan pemboleh ubah daripada segi nilai kod sebenar.

Reka bentuk komposit putaran tengah (CCRD) 5-aras-2-faktor digunakan untuk mengkaji nilai optimum penghidrogenan LNR. Reka bentuk CCRD ini terdiri daripada 13 ulangan eksperimen dengan lapan titik faktorial, enam titik paksi dan enam titik pusat. Analisis varians (ANOVA) telah dilakukan untuk menentukan perbezaan signifikan

JADUAL 1. Julat parameter serta aras untuk CCRD

\begin{tabular}{cccccc}
\hline \multirow{2}{*}{ Pemboleh ubah } & -2 & -1 & 0 & +1 & +2 \\
\cline { 2 - 6 } & 45.9 & 50 & 60 & 70 & 74.1 \\
\hline Suhu tindak balas, A $\left({ }^{\circ} \mathrm{C}\right)$ & 5.2 & 6 & 8 & 10 & 10.8 \\
Masa tindak balas, B $(\mathrm{j})$ & \multicolumn{7}{c}{ Aras }
\end{tabular}

antara pemboleh ubah tidak bersandar. Nilai eksperimen dan nilai jangkaan telah dibandingkan untuk memastikan ketepatan model akhir. Proses pengesahan untuk model yang dicadangkan telah dilakukan untuk mengesahkan model akhir.

\section{KEPUTUSAN DAN PERBINCANGAN}

\section{PEMASANGAN MODEL DAN ANALISIS VARIANS (ANOVA)}

Dua faktor tahap masa tindak balas dan suhu telah ditetapkan dalam CCRD. Peratusan penghidrogenan jangkaan dan eksperimental ditunjukkan pada Jadual 2. Nilai-nilai yang diramalkan telah dihasilkan melalui teknik pemasangan model. Penurunan diimida LNR adalah paling tepat diterangkan dalam bentuk model polinomial kuadratik seperti yang ditunjukkan dalam Persamaan 1 (A adalah suhu tindak balas dan B adalah masa tindak balas).

$$
\begin{aligned}
\text { Penghidrogenan }(\%)= & -952.85373+24.8267 A+ \\
& 73.29723 B-0.41250 A B- \\
& 0.17800 A^{2}-3.02500 B^{2}
\end{aligned}
$$

Dalam Persamaan 1, nilai positif pekali menunjukkan kesan sinergi manakala nilai negatif menandakan kesan antagonis bagi parameter tersebut. Nilai pekali penentu $\left(\mathrm{R}^{2}\right)$ bagi model ini adalah 0.9986 , bermaksud $99.86 \%$ bagi jumlah variasi yang diperhatikan dalam tindak balas ini bergantung kepada pemboleh ubah tidak bersandar. Secara statistik, model dengan nilai $\mathrm{R}^{2}$ melebihi 0.9 dianggap sebagai model yang mempunyai nilai korelasi yang tinggi (Mendes et al. 2001). Untuk kajian ini, nilai $\mathrm{R}^{2}$ yang tinggi menunjukkan bahawa data jangkaan dan data eksperimen bagi peratus penghidrogenan adalah diyakini.

Jadual 3 menunjukkan ANOVA bagi model ini. Sesebuah model akan diterima apabila nilai $\mathrm{P}$ adalah signifikan $(p<0.001)$ dan nilai padanan-kurang-tepat adalah tidak signifikan ( $p>0.0001)$ (Lee et al. 2006). Dalam uji kaji ini, model kami adalah diterima dan dianggap tepat kerana

JADUAL 2. Reka bentuk CCRD bagi penurunan diimida terhadap LNR

\begin{tabular}{ccccc}
\hline Bil. & $\begin{array}{c}\text { Suhu tindak balas, } \\
\mathrm{A}\left({ }^{\circ} \mathrm{C}\right)\end{array}$ & $\begin{array}{c}\text { Masa tindak balas, } \\
\mathrm{B}(\mathrm{j})\end{array}$ & \multicolumn{2}{c}{ Penghidrogenan $(\%)$} \\
\cline { 4 - 5 } 1 & 60.0 & 8.0 & Eksperimental & Jangkaan \\
2 & 60.0 & 8.0 & 91.2 & 90.7 \\
3 & 60.0 & 5.2 & 91.0 & 90.7 \\
4 & 60.0 & 8.0 & 65.9 & 66.1 \\
5 & 50.0 & 6.0 & 90.0 & 90.7 \\
6 & 70.0 & 6.0 & 50.1 & 50.6 \\
7 & 70.0 & 10.0 & 71.2 & 70.4 \\
8 & 45.9 & 8.0 & 55.1 & 54.5 \\
9 & 60.0 & 8.0 & 53.6 & 52.8 \\
10 & 50.0 & 10.0 & 91.0 & 90.7 \\
11 & 74.1 & 8.0 & 67.0 & 66.9 \\
12 & 60.0 & 8.0 & 56.5 & 57.4 \\
13 & 60.0 & 10.8 & 90.3 & 90.7 \\
\hline
\end{tabular}


JADUAL 3. ANOVA bagi model

\begin{tabular}{lcccrc}
\hline Sumber & Jumlah kuadrat & Darjah kebebasan & Purata kuadrat & Nilai-F & Nilai-P \\
\hline Model & 3175.82 & 5 & 635.16 & 1005.67 & $<0.0001$ \\
Suhu tindak balas, A & 22.12 & 1 & 22.12 & 35.02 & 0.0006 \\
Masa tindak balas, B & 0.69 & 1 & 0.69 & 1.10 & 0.3295 \\
$\mathrm{AB}$ & 272.25 & 1 & 272.5 & 431.06 & $<0.0001$ \\
$\mathrm{~A}^{2}$ & 2204.10 & 1 & 2204.10 & 3489.82 & $<0.0001$ \\
$\mathrm{~B}^{2}$ & 1018.50 & 1 & 1018.50 & 1612.63 & $<0.0001$ \\
Baki & 4.42 & 7 & 0.63 & - & - \\
Padanan-tidak-tepat & 3.34 & 3 & 1.11 & 4.12 & 0.1023 \\
Ralat tulen & 1.08 & 4 & 0.27 & - & - \\
Jumlah pembetulan & 3180.24 & 12 & - & - & - \\
\hline
\end{tabular}

mempunyai nilai regresi yang signifikan $(p<0.001)$ dan nilai padanan-tidak-tepat yang tidak signifikan $(p=0.1023)$. Parameter suhu tindak balas (A) dan masa tindak balas (B) dirujuk sebagai kesan linear, interaksi dan kuadratik. Maklumat ini menunjukkan bahawa kedua-dua parameter tersebut adalah bersandaran antara satu sama lain. Dalam kajian ini, hanya sebutan $\mathrm{B}$ didapati tidak signifikan ( $p>0.05$ ) berbanding sebutan lain $\left(\mathrm{A}, \mathrm{AB}, \mathrm{A}^{2}\right.$ and $\left.\mathrm{B}^{2}\right)$ yang signifikan $(p<0.05)$.

Rajah 2 menunjukkan hubungan korelasi yang baik antara penukaran peratusan HLNR (\%) secara eksperimen dan jangkaan. Taburan data yang linear juga merupakan salah satu ciri model yang tepat dan diterima (Salinas et al. 2016). Dengan itu, model ini seterusnya digunakan untuk mengkaji kesan setiap parameter dan pengaruhnya dalam penghidrogenan LNR.

\section{KESAN PARAMETER TINDAK BALAS}

Graf plot tiga permukaan dimensi (3D) yang dijana oleh model ramalan membantu dalam menerangkan hubungan parameter dalam tindak balas ini (Chou et al. 2010). Graf ini juga boleh digunakan untuk menentukan tahap optimum bagi setiap pemboleh ubah. Bagi model dalam kajian ini, paksi-Z mewakili peratus penghidrogenan (\%) manakala dua lagi parameter (suhu dan masa) dijadikan sebagai paksi lawannya.

Peratusan penghidrogenan didapati bertambah apabila suhu tindak balas dan masa tindak balas ditingkatkan. Pada suhu $60.0^{\circ} \mathrm{C}$ dan masa tindak balas selama 8 jam, peratus penghidrogenan yang maksium berjaya dicapai (91.2\%). Walau bagaimanapun, pada suhu tinggi (melebihi $60.0^{\circ} \mathrm{C}$ ), peratus penghidrogenan didapati berkurang dipercayai disebabkan penguraian bahan tindak balas. Hal ini disebabkan hidrogen peroksida (agen pengoksidaan) cenderung untuk terurai dan menghasilkan radikal bebas pada suhu tinggi (Rempel \& Wang 2017). Radikal bebas yang terhasil akan menggalakkan taut silang berlaku antara segmen olefin pada rantaian poliisoprena sehingga meningkatkan kandungan gel dalam produk (Thitithammawong et al. 2015). Sementara itu, pemanjangan masa tindak balas tidak akan meningkatkan peratus penghidrogenan. Tindak balas yang panjang akan menyebabkan penguraian spesies diimida dalam sistem ini. Hal ini akan memberi kesan

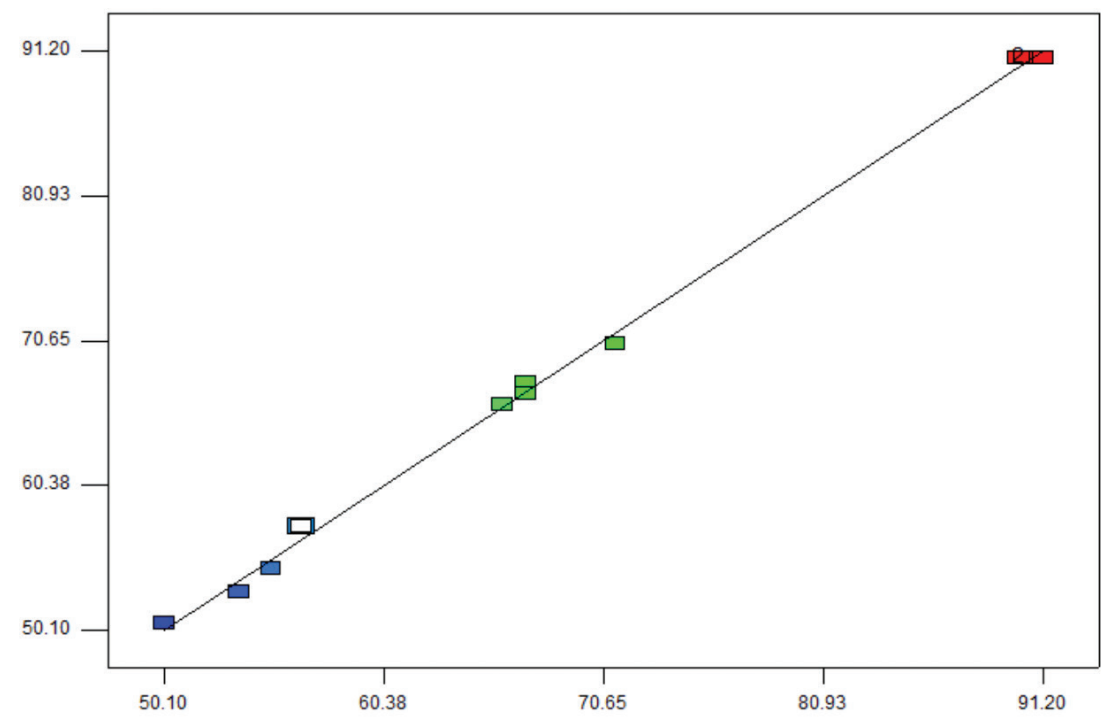

RAJAH 2. Plot korelasi antara data eksperimental dan jangkaan 
kepada progres penghidrogenan kerana sumber hidrogen semakin berkurang (Piya-areetham et al. 2014). Rajah 3 menunjukkan interaksi 3D suhu tindak balas, masa tindak balas dan peratus penghidrogenan. Lengkung parabola pada graf 3D tersebut menandakan bahawa penghidrogenan berlaku pada titik optimum sebelum peratusan penghidrogenan didapati menurun.

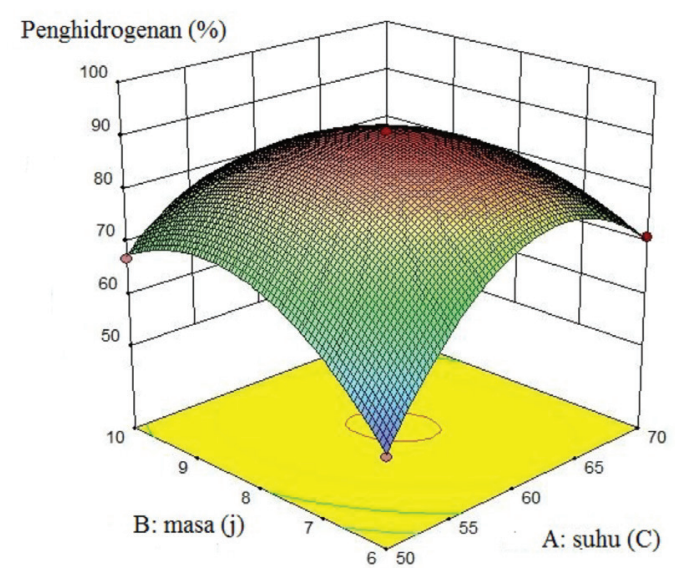

RAJAH 3. Graf 3D bagi hubungan antara pemboleh ubah

\section{KEADAAN OPTIMUM}

Fungsi 'Optimisation' dalam perisian Design Expert digunakan untuk menjangka keadaan yang optimum bagi penghidrogenan LNR. Keadaan parameter yang optimum adalah sebagaimana yang ditunjukkan dalam Jadual 4.

Bagi megesahkan model ini, beberapa siri uji kaji pengesahan telah dijalankan (Jumbri et al. 2015). Jadual 5 menunjukkan nilai uji kaji dan nilai jangkaan bagi set uji kaji tersebut. Perbandingan antara nilai-nilai tersebut menunjukkan nilai selisih yang sedikit. Oleh itu, model empirikal ini boleh digunakan untuk menghuraikan secara berkesan akan hubungan antara pemboleh ubah dan hasil bagi penurunan diimida LNR.

\section{PENCIRIAN HLNR}

FTIR dan spektroskopi NMR digunakan bagi memastikan struktur kimia HLNR. Rajah 4 menunjukkan spektrum FTIR bagi LNR dan HLNR. Puncak $1664 \mathrm{~cm}^{-1}$ pada LNR mewakili regangan $\mathrm{C}=\mathrm{C}$. Keamatan yang rendah pada isyarat yang sama (pengurangan unit $\mathrm{C}=\mathrm{C}$ ) dalam spektrum HLNR berbanding LNR menunjukkan bahawa penghidrogenan telah berlaku (Chen et al. 2013).

Rajah 5 menunjukkan spektrum ${ }^{1} \mathrm{H}$ NMR untuk LNR dan HLNR. Bagi spektrum LNR, puncak metil, metilina dan proton olefinik bagi unit poliiisoprena masingmasing muncul pada $1.7,2.1$ dan 5.3 ppm. Selepas penghidrogenan, keamatan puncak pada 5.3 ppm didapati berkurang yang menerangkan tentang kehilangan unit tidak tepu pada rantaian poliiisoprena (Azhar et al. 2015). Tambahan pula, keamatan puncak 1.7 ppm yang mewakili proton metil dalam struktur cis-1,4 polyisoprena turut berkurang. Isyarat baru muncul pada anjakan kimia antara 0.8 dan $1.5 \mathrm{ppm}$, menjelaskan tentang persekitaran proton yang baru (metil dan metilina) selepas proses penghidrogenan.

\section{KESIMPULAN}

Penurunan diimida terhadap LNR telah berjaya dilakukan dan dioptimumkan menggunakan RSM berdasarkan manipulasi suhu tindak balas dan masa tindak balas. Nilai $\mathrm{R}^{2}$ yang tinggi (0.9986) membuktikan bahawa nilai eksperimen dan nilai jangkaan adalah hampir sepadan. Berdasarkan ANOVA, model yang dihasilkan adalah berguna untuk meramalkan peratus penghidrogenan pada mana-mana keadaan tindak balas dalam julat uji kaji. Lebih banyak keadaan optimum boleh dikaji pada masa akan datang seperti nisbah bahan tindak balas sumber diimidia dan kandungan getah kering.

\section{PENGHARGAAN}

Para penulis ingin berterima kasih kepada Universiti Kebangsaan Malaysia (UKM) atas geran penyelidikan

JADUAL 4. Keadaan optimum bagi penghidrogenan LNR

\begin{tabular}{|c|c|c|c|c|c|}
\hline \multirow[t]{2}{*}{ Bil. } & \multirow{2}{*}{$\begin{array}{c}\text { Suhu tindak balas, } \\
\mathrm{A}\left({ }^{\circ} \mathrm{C}\right)\end{array}$} & \multirow{2}{*}{$\begin{array}{c}\text { Masa tindak balas, } \\
\text { B (j) }\end{array}$} & \multicolumn{2}{|c|}{ Penghidrogenan $(\%)$} & \multirow[t]{2}{*}{ Sisihan } \\
\hline & & & Uji kaji & Jangkaan & \\
\hline 1 & 55.9 & 6.77 & 81.4 & 80.2 & 1.2 \\
\hline
\end{tabular}

JADUAL 5. Pengesahan model

\begin{tabular}{cccccc}
\hline Bil. & $\begin{array}{c}\text { Suhu tindak balas, } \\
\mathrm{A}\left({ }^{\circ} \mathrm{C}\right)\end{array}$ & $\begin{array}{c}\text { Masa tindak balas, } \\
\mathrm{B}(\mathrm{j})\end{array}$ & \multicolumn{2}{c}{ Penghidrogenan $(\%)$} & \multirow{2}{*}{ Selisih } \\
\cline { 4 - 5 } & 55 & 6 & 68.5 & 68.9 & \\
\hline 1 & 65 & 6 & 79.0 & 78.8 & 0.40 \\
2 & 55 & 7 & 80.2 & 80.5 & 0.30 \\
\hline
\end{tabular}




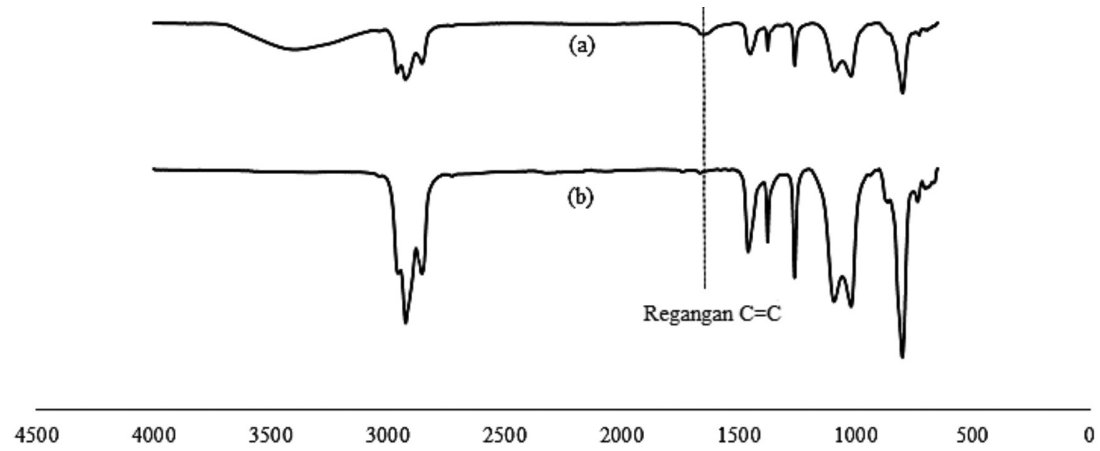

RAJAH 4. Spektrum FTIR bagi LNR (a) dan HLNR (b)

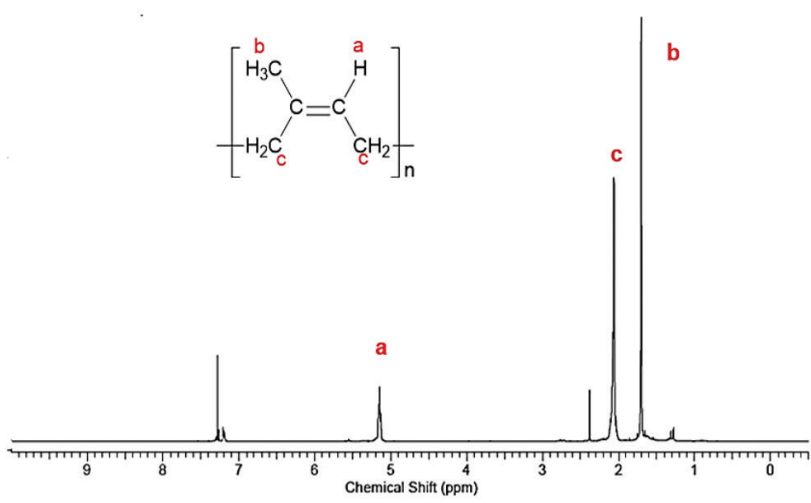

(a)

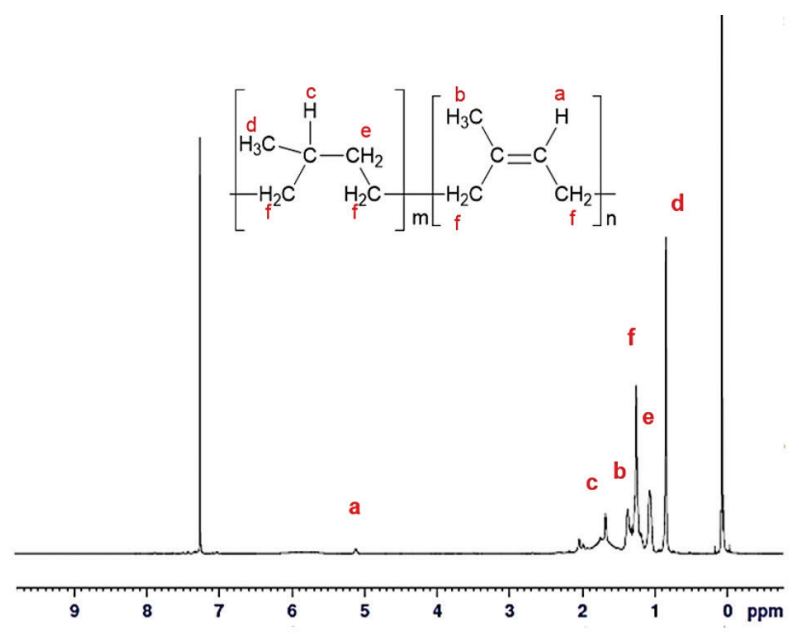

(b)

RAJAH 5. Spektrum ${ }^{1} \mathrm{H}$ NMR bagi LNR (a) dan HLNR (b)

yang diberikan (GUP-2015-020 dan FRGS/1/2016/STG01/ $\mathrm{UKM} / 02 / 4)$ dan Centre for Research and Instrumentation (CRIM) di UKM bagi kemudahan instrumentasi.

\section{RUJUKAN}

Alshaibani, A.M., Yaakob, Z., Alsobaai, A.M. \& Sahri, M. 2014. Optimization of pd-b $/ \gamma$-al 2 o 3 catalyst preparation for palm oil hydrogenation by response surface methodology (RSM) Journal of Chemical Reactor Engineering 31(1): 69-78.

Azhar, N.H.A., Jamaluddin, N., Md Rasid, H., Yusof, M., Jefri, M. \& Yusoff, S.F.M. 2015. Studies on hydrogenation of liquid natural rubber using diimide. International Journal of Polymer Science 2015: 243038.

Cepeda, E.A. \& Calvo, B. 2008. Sunflower oil hydrogenation: Study using response surface methodology. Journal of Food Engineering 89(4): 370-374.

Chen, D., Shao, H., Yao, W. \& Huang, B. 2013. Fourier transform infrared spectral analysis of polyisoprene of a different microstructure. International Journal of Polymer Science 2013: 937284

Chou, K.W., Norli, I. \& Anees, A. 2010. Evaluation of the effect of temperature, $\mathrm{NaOH}$ concentration and time on solubilization of palm oil mill effluent (POME) using response surface methodology (RSM). Bioresource Technology 101(22): 8616-8622.
Fainleib, A., Pires, R.V., Lucas, E.F. \& Soares, B.G. 2013. Degradation of non-vulcanized natural rubber - renewable resource for fine chemicals used in polymer synthesis. Polimeros 23: 441-450.

Han, Y., Su, L., Mao, L., Zhang, L. \& Yue, D. 2014. Self-crosslinking hydrogenated nitrile-butadiene rubber latex/polyvinyl chloride emulsion composite film and its properties. PolymerPlastics Technology and Engineering 53(3): 306-311.

Ibrahim, S., Rubber, M. \& Ibrahim, S. 2016. Chemical depolymerisation of natural rubber in biphasic medium. Advanced Materials Research 1024: 193-196.

Jamaluddin, N., Mohd Yusof, M.J., Abdullah, I. \& M. Yusoff, S.F. 2016. Synthesis, characterization, and properties of hydrogenated liquid natural rubber. Rubber Chemistry and Technology 89(2): 227-239.

Ji, M., Yue, D., Wu, X., Zhao, S., Sun, S. \& Zhang, L. 2017. Structure and performance of hydrogenated natural rubber prepared by the latex method. Plastics, Rubber and Composites 46(6): 245-250.

Jumbri, K., Rozy, M.F.A. \& Ashari, S.E. 2015. Optimisation and characterisation of lipase- catalysed synthesis of a kojic monooleate ester in a solvent-free system by response surface methodology. PloS One 10(12): 1-13.

Kargarzadeh, H., Ahmad, I. \& Abdullah, I. 2014. Liquid rubbers as toughening agents. Micro and Nanostructures Epoxy/ Rubber Blends 1: 31-52. 
Lee, W.C., Yusof, S., Hamid, N.S.A. \& Baharin, B.S. 2006. Optimizing conditions for enzymatic clarification of banana juice using response surface methodology (RSM). Journal of Food Engineering 73(1): 55-63.

Leimgruber, S. \& Trimmel, G. 2015. Olefin metathesis meets rubber chemistry and technology. Monatshefte für ChemieChemical Monthly 146(7): 1081-1097.

Mendes, L.C., De Menezes, H.C., Aparecida, M. \& Da Silva, A.P. 2001. Optimization of the roasting of robusta coffee (C. canephora conillon) using acceptability tests and RSM. Food Quality and Preference 12(2): 153-162.

Onoji, S.E., Iyuke, S.E. \& Igbafe, A.I. 2016. Hevea brasiliensis (Rubber seed) oil: Extraction, characterization, and kinetics of thermo-oxidative degradation using classical chemical methods. Energy \& Fuels 30(12): 10555-10567.

Piya-areetham, P., Rempel, G.L. \& Prasassarakich, P. 2014. Hydrogenated nanosized polyisoprene as a thermal and ozone stabilizer for natural rubber blends. Polymer Degradation and Stability 102: 112-121.

Radabutra, S., Saengsuwan, S., Jitchati, R. \& Kalapat, M. 2017. Preparation and characterization of modified telechelic natural rubber-based pressure-sensitive adhesive. Journal of Adhesion Science and Technology 31(24): 2682-2696.

Rempel, G.L. \& Wang, H. 2017. Nitrile rubber latex blends: Preparation, characterization and applications. In Rubber Nano Blends, edited by Markovic, G. \& Visakh, P.M. Springer Series on Polymer and Composite Materials. Springer, Cham. pp. 67-88.

Sakorn, S., Rempel, G.L., Prasassarakich, P. \& Hinchiranan, N. 2016. Poly (styrene)-and poly (styrene-co-methyl methacrylate)-graft-hydrogenated natural rubber latex: Aspect on synthesis, properties, and compatibility. Journal of Vinyl and Additive Technology 22(2): 100-109.

Salinas, M.V., Zuleta, A., Ronayne, P. \& Puppo, M.C. 2016. Wheat bread enriched with organic calcium salts and inulin. A bread quality study. Journal of Food Science and Technology 53(1): 491-500.

Simma, K., Rempel, G.L. \& Prasassarakich, P. 2009. Improving thermal and ozone stability of skim natural rubber by diimide reduction. Polymer Degradation and Stability 94(11): 19141923.

Tahir, N.A.M., Azhar, N.H.A., Rasidi, H.M. \& Yusoff, S.F.M. 2017. Penghidrogenan getah asli cecair dan getah asli cecair terepoksida menggunakan diimida. Journal of Polymer Science and Technology 2(1): 1-10.

Taksapattanakul, K., Tulyapitak, T., Phinyocheep, P., Ruamcharoen, P., Ruamcharoen, J., Lagarde, F. \& Daniel, P. 2017. The effect of percent hydrogenation and vulcanization system on ozone stability of hydrogenated natural rubber vulcanizates using Raman spectroscopy. Polymer Degradation and Stability 141: 58-68.
Thitithammawong, A., Rungvichaniwat, A. \& Srangkum, S. 2015. Properties of dual cured polyurethane film coatings based on natural rubber. Macromolecular Symposia 354: 354-360.

Thongnuanchan, B., Ninjan, R., Kaesaman, A. \& Nakason, C. 2015. A novel method to crosslink natural rubber latex adhesive at ambient temperature. Polymer Bulletin 72(1): 135-155.

Trovatti, E., Cunha, A.G., Carvalho, A.J.F. \& Gandini, A 2017. Furan-modified natural rubber: A substrate for its reversible crosslinking and for clicking it onto nanocellulose. International Journal of Biological Macromolecules 95: 762-768.

Wu, W., Zhai, Y., Zhang, Y. \& Ren, W. 2014. Mechanical and microwave absorbing properties of in situ prepared hydrogenated acrylonitrile-butadiene rubber/rare earth acrylate composites. Composites Part B: Engineering 56: 497-503.

Yuan, D., Ding, J., Mou, W., Wang, Y. \& Chen, Y. 2017. Biobased polylactide/epoxidized natural rubber thermoplastic vulcanizates with a co-continuous phase structure. Polymer Testing 64: 200-206.

Yusof, M.J.M., Abdullah, I. \& Yusoff, S.F.M. 2017. Sintesis dan pencirian getah asli cecair terhidrogen untuk adunan polimer. Sains Malaysiana 46(10): 1817-1823.

Zirnstein, B., Tabaka, W., Frasca, D., Schulze, D. \& Schartel, B. 2018. Graphene/hydrogenated acrylonitrile-butadiene rubber nanocomposites: Dispersion, curing, mechanical reinforcement, multifunctional filler. Polymer Testing 66: 268-279.

Muhammad Jefri Mohd Yusof, Nur Aidasyakirah Mohd Tahir, Fazira Firdaus \& Siti Fairus M. Yusoff*

Pusat Pengajian Sains Kimia dan Teknologi Makanan

Fakulti Sains dan Teknologi

Universiti Kebangsaan Malaysia

43600 UKM Bangi, Selangor Darul Ehsan

Malaysia

Siti Fairus M. Yusoff*

Polymer Research Centre (PORCE)

Fakulti Sains dan Teknologi

Universiti Kebangsaan Malaysia

43600 UKM Bangi, Selangor Darul Ehsan

Malaysia

Pengarang untuk surat-menyurat; email: sitifairus@ukm.edu.my

Diserahkan: 27 Mac 2018

Diterima: 17 Mei 2018 